\title{
1 Sensitivity to perturbations of a cell 2 migration under temporal regulation
}

3

4 Clément Dubois $^{* 1}$, Shivam Gupta ${ }^{* 2}$, Andrew Mugler ${ }^{\# 2}$ and Marie-Anne Félix ${ }^{\# 1}$

5

6 1: Institut de Biologie de l'Ecole Normale Supérieure, CNRS, Inserm, 75005 Paris, 7 France.

8 2: Department of Physics and Astronomy, Purdue University, West Lafayette, Indiana. 9

11 \#: Correspondence: felix@bio.ens.psl.eu; amugler@purdue.edu 


\section{2}

13

14

15

16

\section{Abstract}

Few studies have measured the robustness to perturbations of the final position of a long-range migrating cell. In the nematode Caenorhabditis elegans, the QR neuroblast migrates anteriorly in the young larva, while undergoing three rounds of division. The daughters of QR.pa stop their migration at an anterior body position and acquire a neuronal fate. Previous studies showed that the migration stops upon expression of the Wnt receptor MIG-1, which surprisingly is not induced by positional cues but by a timing mechanism (Mentink et al. 2014). Given this temporal regulation, we wondered 1) how precise QR.pax positioning is when confronted with various challenges, such as stochastic noise, environment or body size variation and 2) whether QR.pax position varies among $C$. elegans wild isolates. We find that the variance of QR.pax final position is similar to that of other long-range migrating neurons. Its mean position undergoes a slight posterior shift at higher temperature, while its variance is greatly increased following sustained starvation at hatching. We manipulated body size using mutants and tetraploid animals. As expected from the temporal mechanism, smaller mutants display anteriorly shifted QR.pax cells, while longer mutants and tetraploids display posteriorly shifted QR.pax cells. Using a mathematical model, we show however that body size variation is partially compensated. We find that cell speed is indeed altered in body size mutants. Finally, we could detect highly significant variation among $C$. elegans wild isolates. Overall, this study reveals that the final cell position of QR.pax shows some degree of sensitivity to external perturbations and natural genetic 3 variation. 
Cell migration is a key process during the development of many animal tissues. Much is known about the cues that confer directionality to the migration (Whangbo and Kenyon, 1999; Branda and Stern, 2000; Duchek et al., 2001; Pani and Goldstein, 2018; Szabó and Mayor, 2018; Kim et al., 2019), accuracy in gradient sensing and directionality (Barkai and Leibler, 1997; Endres and Wingreen, 2008) and the signal transduction and cytoskeletal dynamics behind the movement (Abercrombie et al., 1970; Ridley et al., 2003; Svitkina, 2018; van Helvert et al., 2018). In comparison, the termination of migration has been little studied, although it is obviously of key importance for final cell and organ position (Meighan and Schwarzbauer, 2007; Aman and Piotrowski, 2010; Inamura et al., 2012; Kikuchi et al., 2015; Paksa et al., 2016). Termination of most cell migrations is thought to be spatially triggered by homogenous concentrations of the guiding cues (Doitsidou et al., 2002), adhesion to a specific target cell (Rohrschneider and Nance, 2013) and/or physical barriers (Halfter et al., 2002; Paksa et al., 2016), but in a recent case was shown to be regulated independently of spatial cues, in a time-dependent fashion (Mentink et al., 2014, see below).

The occurrence of cell migration begs the question of the degree of precision in final cell position. The degree of sensitivity of a trait to a given perturbation - or conversely its precision or robustness - is a fundamental characteristic of biological systems (Félix and Wagner, 2008). Although defects in the direction of cell migration are often reported (Burke et al., 2015), few studies have measured the precision in the length of migration and the final position of the cell (Branda and Stern, 2000; Grimbert et al., 2016; Paksa et al., 2016; Lau et al., 2020). Moreover, while the majority of cell migration studies explore the effect of genetic or experimental perturbations, they have not addressed more ecologically and evolutionary relevant types of perturbation, such as environmental, stochastic, or natural genetic variation.

The QR neuroblast is a cell that migrates a long distance from the posterior to a more anterior position during the first larval stage of the nematode Caenorhabditis elegans. Three rounds of $\mathrm{QR}$ cell division take place during or at the end of the migration (Sulston and Horvitz, 1977). The progeny are named according to their anterior or posterior position at each successive cytokinesis: thus QR.p is the posterior daughter of QR, and QR.pa the anterior daughter of QR.p. Finally, the daughter cells of QR.pa, called QR.paa and QR.pap (hereafter called QR.pax), acquire a neuronal 
67 identity (Chalfie and Sulston, 1981; White et al., 1986). Much is known about the 68 signaling pathways, transcription factors and cytoskeleton regulating their posterior-toanterior direction and orientation of migration (Middelkoop and Korswagen, 2014; Josephson et al., 2016; Rella et al., 2016). Concerning the termination of migration and final cell positioning, the posterior-to-anterior QR.pa lineage stops upon expression of the Wnt receptor MIG-1 (Mentink et al., 2014). Surprisingly, the expression of mig-1 in QR.pa is not induced by the cell reaching a certain position in the body, but by a temporal regulation, independently of cell position. Indeed, preventing QR migration or increasing its speed does not alter the timing of mig-1 expression (Mentink et al., 2014). After QR.pa stops migrating, its daughter cells QR.pax separate in a dorso-ventral direction while crossing each other in an anteroposterior direction (Rella et al., 2016; Altun and Hall, 2020); they then differentiate without further change in cell body position (Figure 1).

We here probe the sensitivity of this system to various perturbations of ecological and evolutionary relevance. We score both the mean and the distribution of the final cell position.

First, noise, or stochastic variation, is measured by variation in the trait among isogenic animals grown in the same environment (Spudich and Koshland, 1976; McAdams and Arkin, 1997; Elowitz et al., 2002). In our study, we measured the degree of robustness (or sensitivity) of QR.pax final position by comparing its variance to that of other migrating neuronal cell bodies: those of ALMR, BDUR, CANR and HSNR (later called ALM, BDU, CAN and HSN) (Sulston et al., 1983; Hedgecock et al., 1987) (Figure 1.D).

Second, we perturbed the external environment in two ways. We first tested the effect of an environmental perturbation that is highly relevant in the wild, namely different temperatures, from $15^{\circ} \mathrm{C}$ to $25^{\circ} \mathrm{C}$. Second, we tested the effect of starvation at hatching, before QR migration. After embryonic development inside its egg shell, $C$. elegans hatches in the first larval stage (L1) in the shape of a small worm. If no food is provided, the larva enters a developmental arrest program that can last for several days, prior to QR migration and first division (Johnson et al., 1984; Baugh, 2013). QR migration starts shortly after feeding the animal. We thus tested the robustness of QR.pa final position to this temporary developmental arrest after hatching. 
101 final cell position relative to other landmarks along the antero-posterior axis - provided 102 that cell migration occurs at the same speed in animals of different body sizes. The expectation is that in longer animals QR.pa stops in a more posterior position relatively 104 to body landmarks; and in smaller animals at a more anterior position. To address the effect of body size on the relative position of QR.pax, we used different body size mutants in the reference genetic background N2. In parallel, we developed a mathematical model of the expected relationship between body size and QR.pax final position, taking into account larval growth during cell migration.

Fourth, we explored natural variation using a panel of $C$. elegans wild isolates.

110 The study of wild isolates reveals natural variation for phenotypic traits (Hodgkin and 111 Doniach, 1997; Farhadifar et al., 2015; Cook et al., 2016; Gimond et al., 2019; Lee et 112 al., 2019) and different genotypes can reveal different sensitivities to perturbations 113 (Braendle and Félix, 2008). So far, QR.pax final position had only been measured in 114 the laboratory-evolved reference background N2 and mutants from this strain. 115 Laboratory adaptation may alter many phenotypes in many organisms including 116 Drosophila melanogaster (Stanley and Kulathinal, 2016), Caulobacter crescentus 117 (Marks et al., 2010) or Caenorhabditis elegans (McGrath et al., 2009; Sterken et al., 118 2015). We therefore wondered to which extent the final position of QR.pax evolved 119 within C. elegans; and whether the degree of robustness to noise and environmental 120 perturbations was a shared feature between laboratory adapted genotypes and wild 121 isolates.

We find that the variance of QR.pax final position is similar to that of other 123 neurons that migrate at a long-range during embryogenesis. At higher temperatures, 124 the mean position of QR.pax undergoes a slight posteriorly shift, while its variance is 125 increased by a starvation treatment after hatching, showing that the system is not fully 126 robust to external perturbations. Moreover, as expected from the temporal mechanism 127 of migration termination, smaller mutants display more anterior QR.pax cells, while 128 longer mutants and tetraploids display posteriorly shifted QR.pax cells. Finally, we 129 could detect highly significant variation among C. elegans wild isolates that was not 130 significantly explained in our tested panel by variation in body size. 


\section{Materials \& methods}

\section{C. elegans strains:}

Caenorhabditis elegans were grown at $20^{\circ} \mathrm{C}$ on $55 \mathrm{~mm}$ diameter Petri dishes with NGM, fed on Escherichia coli OP50 according to the standard procedures (Brenner, 1974). To investigate the relationship between body size and QR.pax final position, we selected a list of mutations in the reference genetic background N2 known to affect egg size and a priori not cell migration: JJ1271 glo-1(zu391) (Hermann et al., 2005), GL302 cid-1(rf34) (Olsen et al., 2006), RB2488 amph-1(ok3443) (The C. elegans Deletion Mutant Consortium, 2012), RB1658 mca-3(ok2048) (The C. elegans Deletion Mutant Consortium, 2012) BA819 spe-11(hc77) (L'Hernault et al., 1988), GH383 glo3(zu446) (Rabbitts et al., 2008), JT513 nrf-5(sa513) (Choy and Thomas, 1999), JT73 itr-1(sa73) (Iwasaki et al., 1995), RT362 rme-4(b1001) (Sato et al., 2008), JK4545 larp1(q783) (Nykamp et al., 2008), CB30 sma-1(e30) (Brenner, 1974), RB1977 fln1(ok2611) (The C. elegans Deletion Mutant Consortium, 2012), CB185 Ion-1(e185) (Brenner, 1974) and the tetraploid 4A:4X strain SP346 (Madl and Herman, 1979).

To investigate the natural variation for the trait, we used the following wild isolate strains (Cook et al., 2017) CB4856, CB4932, CX11271, CX11314, ECA189, ECA191, ECA36, ECA363, ECA369, ECA372, ECA396, EG4725, JT11398, JU1200, JU1242, JU258, JU363, JU367, JU775, JU830, JU1393, LKC34, MY10, NIC199, NIC251, NIC256, NIC268, PB303, PB306, QG2075, QG556, QX1791, QX1793, QX1794, WN2001, XZ1513, XZ1514, XZ1515, XZ1516.

The strain NH646 ayls9[Pegl-17::gfp + dpy-20(+)]; dpy-20(e1282ts) (Branda and Stern, 2000) with a Q lineage GFP reporter was also used in this study (kind gift of the Korswagen laboratory). The strain GOU174 cas/s35[Pgcy-32::mCherry, unc76(+)] X; zdls5[Pmec-4::gfp, lin-15(+)]l (Zhu et al., 2016) was used to observe cell body and axon of mechanosensory neurons including AVM (QR.paa) (kind gift from the Ou laboratory).

\section{QR.pax final position measurements in N2 mutants and wild isolates:}

QR.paa and QR.pap final positions were measured using Nomarski microscopy of late L1 larval stage animals mounted on $3 \%$ agar pads and immobilized with $1 \mathrm{mM}$ sodium azide. At this stage, the $V$ seam cells have divided once, $Q R$. paa has reached its final 
163

164

165

166

167

168

169

170

171

172

173

174

175

176

177

178

179

180

181

182

183

184

185

186

187

188

189

190

191

192

193

194

195

ventral position and QR.pap its final dorsal position in the animal. QR.pax final position is the mean position of QR.pap and QR.paa in each individual, measured with a relative scale based on the V-derived seam cells (Harris et al., 1996; Whangbo and Kenyon, 1999; Coudreuse et al., 2006; Mentink et al., 2014). Note that the relative position of QR.paa to QR.pap does not change when the long-range migration of their ancestors is affected (Fig. S3 in Mentink et al., 2014). We constructed a semi-discrete scale from the pharynx (0) to the rectum (27), based on the repeated pattern formed by the nuclei of the seam cells and hyp7 cells. A half value is attributed when the nucleus is between two landmarks. In some cases, we also measured distances in microns.

\section{Robustness to noise:}

We measured the variance of QR.pax position when faced with stochastic noise and compared it to that of other neurons migrating during embryogenesis: BDU, ALM, CAN and HSN (Sulston et al., 1983; Hedgecock et al., 1987). These neurons are easily recognizable and are in the same environment as QR.pax. We could use the same relative scale to measure the position of these cells' bodies and compare variance between them. We performed a Levene's test for equality of variance to measure the differences of variance between strains and cell positions, adjusted with Bonferroni correction for multiple testing. The experiment was performed in two replicates and those were merged as there was no replicate effect on the variance (see Supp. Table 1).

\section{Robustness to environmental perturbations:}

In order to test the robustness of QR.pax final position to growth at different temperatures, L1 larvae from the N2 strain and three wild isolates were transferred from $20^{\circ} \mathrm{C}$ to $15^{\circ} \mathrm{C}, 20^{\circ} \mathrm{C}$ or $25^{\circ} \mathrm{C}$ one generation before scoring. We repeated this experiment three independent times. We performed a two-way ANOVA to explain QR.pax final position according to temperature of growth (considered as a continuous variable), strain, temperature $x$ strain interaction and replicate experiments. The effect of the replicates adds variability in the measurements but not in a particular direction (see Supp. Table 1). To consider the variability in the response to temperature, we modeled the replicate effect as a random effect. We tested the correlation between QR.pax final position and the absolute value of the latitude of the wild isolate sampling 
location (as a proxy for the temperature of origin), using Pearson's product-moment correlation test.

To test the robustness to transient developmental arrest in the L1 stage, cultures were grown until food depletion. Once food was exhausted on the plate, we maintained the population under starvation for two more days. Note that this protocol avoided a bleach treatment that may affect the larvae independently of the starvation period. Then, we collected larvae in M9 buffer and plated them onto NGM agar plates with $E$. coli OP50. We scored QR.pax position six to eight hours later, only when $V$ seam cells divided once, Pn cells migrated ventrally, QR.pap reached the dorsal part of the animal and QR.paa the ventral part. We thus did not score the most delayed animals - note that rejecting these animals is unlikely the reason for the observed increased variance in QR.pax position. In contrast to the bleaching method, small larvae may have access to a minimal amount of food before starvation allowing the beginning of QR migration. We found that using this protocol, $58 \%$ of animals have QR.pa divided above the seam cell V1, 24\% with QR.pa at the top of V2, $12 \%$ at the top of $\mathrm{V} 3$ and $6 \%$ at $\mathrm{V} 4$ ( $\mathrm{n}=50$ worms). We performed a Levene's test for equality of variances to measure the effect of the strain and the starvation condition on QR.pax final position variance, adjusted with Bonferroni correction for multiple testing. During this experiment, the position of BDU, ALM, CAN, HSN and QR.pax was measured in XZ1516 in parallel. The same method was then used in an independent experiment using the genotype N2.

\section{Distance measurements:}

We first measured egg length in a set of mutants with a putatively altered embryo size (see list above) and compared their size to that of N2 using a two-sided t-test with Bonferroni adjustment of the $p$-value for multiple comparisons. Most body size mutants concern larval growth and not earlier stages. Live embryos of cid-1(rf34), glo-3(zu446), itr-1(sa73), mca-3(ok2048), rme-4(b1001), spe-11(hc77) mutants did not show significant differences in length compared to N2 and were thus rejected (Figure S2A).

We measured QR.pax final position in the remaining mutants with significant differences in egg size. Three mutants had gross defects and we decided to discard them further from the analysis: amph-1(ok3443) and nrf-5(sa513) exhibited several defects including cell migration defects for BDU, ALM and/or dorsal-ventral migration of QR.paa and QR.pap; glo-1(zu391) mutants had long eggs but small and sick larvae. 
We then compared QR.pax final position of the mutants to N2 with a two-sided t.test and p-values were adjusted with Bonferroni method for multiple comparisons.

To test the correlation between egg size and L1 larva body size, we measured

232 the distance between the rectum and the end of the pharynx, corresponding to the 233 area of migration of the QR neuroblast from 27 to 0 in our relative scale. Plates 234 containing eggs were washed several times and transferred onto a fresh plate in order 235 to only keep unhatched embryos. Freshly hatched larvae (0-20 min) were mounted on 236 agar pads immobilized with $1 \mathrm{mM}$ sodium azide and measured from the pharynx to the 237 rectum, or transferred to fresh plates to perform the measurements $6 \mathrm{~h}$ after hatching.

To test whether body size differentially affected each step of the migration, we measured the distance between the rectum, QR.pp (QR.p site of division), QR.pa and the pharynx, in worms where QR.pa had just divided and the QR.pp apoptotic body was still present. To visualize the cells in body size mutants, we introgressed ayls9[Pegl-17::gfp,dpy-20+] in sma-1(e30) and lon-1(e185) background by crossing CB30 and CB185 strains, respectively, with NH646. The strains of genotype ayls9 sma-1(e30) and lon-1(e185); ayls9 were used to estimate cell velocity of QR by measuring the distance between the rectum, the $\mathrm{QR}$ lineage and the pharynx at $3 \mathrm{~h}$ and 6h after hatching, corresponding to QR.p lineage long-range migration.

To investigate the effect of QR.pax final position on neuronal differentiation phenotypes, we applied the starvation protocol described above to the strain GOU174 wiht a GFP marker for mechanosensory neurons and monitored the axons of AVM 250 (QR.paa), PVM, ALM and PLM. We measured the relative position of AVM by dividing 251 the Pharynx-to-AVM distance by the Pharynx-to-ALM distance. We measured AVM position in the L3 stage, 31 hours after food provisioning to starved worms, with two independent replicate experiments. The control population was obtained by washing plates with M9 to only keep embryos on NGM. Then the embryos were allowed to hatch and feed on OP50 for 41 hours before phenotyping. We performed a Levene's test for equality of variances to measure the effect of starvation on the variance in AVM

257 relative position in each replicate and in the whole dataset. The effect of starvation and 258 AVM final position on the axon overlapping phenotype was analyzed with a generalized mixed model.

Pictures and measurements were performed with the camera Photometrics 261 CoolSNAP ES (Roper Scientific) and software Nikon NIS element D (version 3.1). The 
262 size in pixel was then converted to micrometers after calibration $(\operatorname{Size}(\mu \mathrm{m})=$ 263 Size $(p x) / 9.84)$.

264 Relationship between QR.pax final position and distance measurements:

265 We used the data of egg length, pharynx-to-rectum distance (hereafter called P-to-R) 266 at two timepoints ( 0 and 6 hrs) and QR.pax final position of each strain to test 267 relationships between these variables. The different size measurements and QR.pax 268 final positioning was not measured in the same individual but in an isogenic population. 269 To consider the variance in both axes for the regressions we used a bootstrapping 270 approach with 1000 iterations. Each iteration was made by subsampling 20 egg size 271 measurements, P-to-R distance at hatching, 6 hours after hatching and QR.pax final 272 position per genotype. Model 1 regression (Ordinary Least Square method) was

273 performed between each variable at each iteration. Means, intercepts, slopes, $R^{2}{ }_{a d j}$ 274 and $p$-values generated per iteration were saved for plotting. The median of the 275 bootstrapped $R^{2}$ adj and $p$-values of the regression was used to conclude on the 276 likelihood of the correlation.

\section{Mathematical model for QR.pax final position:}

279 For the no-compensation model, we treated the dynamics of the QR cell lineage as 280 one-dimensional, constant-velocity migration within a growing larva. Taking the 281 pharynx to be stationary at the origin $x=0$ and the rectum to be moving away with constant velocity $u$ due to the growth, the length of the pharynx-to-rectum region evolves in time according to

$$
l(t)=l_{0}+u t
$$

where $I_{0}$ is the length at hatching $(t=0)$. The dynamics of the cell position $x$ are

$$
\frac{\mathrm{d} x}{\mathrm{~d} t}=-v(t)+\frac{x}{l(t)} u
$$

where the first term is the leftward velocity of the cell, and the second term is an effective rightward velocity due to the growth. In the second term we enforce uniform expansion of the larva during growth, such that intermediate points move according to the fraction of the distance to the origin. We assume that the cell begins migrating at a constant velocity $v_{0}$ at a time $t=t$ after hatching and stops migrating at a time $t=T$,

$$
v(t)=\left\{\begin{array}{lr}
0 & t<\tau \\
v_{0} & t \leq \tau \leq T \\
0 & t>T
\end{array}\right.
$$

293 Integrating Eq. 2 gives 


$$
x(t)=\left\{\begin{array}{lr}
l(t) \frac{x_{0}}{l_{0}} & t<\tau \\
l(t)\left[\frac{x_{0}}{l_{0}}-\frac{v_{0}}{u} \ln \left(\frac{l(t)}{l(\tau)}\right)\right] & t \leq \tau \leq T, \\
l(t)\left[\frac{x_{0}}{l_{0}}-\frac{v_{0}}{u} \ln \left(\frac{l(T)}{l(\tau)}\right)\right] & t>T
\end{array}\right.
$$

295 where $x_{0}$ is the initial position of the cell. The relative position on the semi-discrete scale is $p=N x / l$, where $N=27$ (Figure 1B). Inserting Eq. 4, we have

$$
p(t)=\left\{\begin{array}{lr}
p_{0} & t<\tau \\
p_{0}-\frac{N v_{0}}{u} \ln \left(\frac{l(t)}{l(\tau)}\right) & t \leq \tau \leq T \\
p_{0}-\frac{N v_{0}}{u} \ln \left(\frac{l(T)}{l(\tau)}\right) & t>T
\end{array}\right.
$$

where $p_{0}=19$ is the initial position of the cell (Figure 1B). We take $u=(35 \mu \mathrm{m}) /(6$ hours) $=5.8 \mu \mathrm{m} / \mathrm{hr}$ from the experiments (Figure S2E), and $T=2 \mathrm{hr}$ and $T=8 \mathrm{hr}$ (Sulston and Horvitz, 1977; Ou and Vale, 2009; Ebbing et al., 2019) from the literature, leaving only $v_{0}$ as a fit parameter. Figure $2 \mathrm{C}$ (red curve) shows $p$ versus $I_{0}$ from Eq. 5 $(t>T)$ with best-fit value $v_{0}=11.6 \mu \mathrm{m} / \mathrm{hr}$.

For the partial-compensation model, we used Eq. 4 to infer the cell velocity from measurements of $x$ and $I$ at two time points $t_{1}=3 \mathrm{hr}$ and $t_{2}=6 \mathrm{hr}$. Calling $x\left(t_{1}\right)=x_{1}$, $x\left(t_{2}\right)=x_{2}, I\left(t_{1}\right)=I_{1}$, and $I\left(t_{2}\right)=I_{2}$ for short, and recognizing that both $t_{1}$ and $t_{2}$ fall between $T$ and $T$, we have from Eq. 4,

$$
\begin{aligned}
& \frac{x_{1}}{l_{1}}=\frac{x_{0}}{l_{0}}-\frac{v_{0}}{u} \ln \left(\frac{l_{1}}{l(\tau)}\right), \\
& \frac{x_{2}}{l_{2}}=\frac{x_{0}}{l_{0}}-\frac{v_{0}}{u} \ln \left(\frac{l_{2}}{l(\tau)}\right),
\end{aligned}
$$

at each time point. Subtracting Eq. 7 from Eq. 6 gives

$$
\frac{x_{1}}{l_{1}}-\frac{x_{2}}{l_{2}}=\frac{v_{0}}{u} \ln \left(\frac{l_{2}}{l_{1}}\right) \text {. }
$$

Because growth is linear in time (Eq. 1), we have $u=\left(I_{2}-l_{1}\right) /\left(t_{2}-t_{1}\right)$. Inserting this expression into Eq. 8 and solving for $v_{0}$ gives

$$
v_{0}=\left(\frac{x_{1}}{l_{1}}-\frac{x_{2}}{l_{2}}\right) \frac{l_{2}-l_{1}}{\left(t_{2}-t_{1}\right) \ln \left(l_{2} / l_{1}\right)} .
$$

314 Eq. 9 was used to calculate the cell velocities in the lon-1(e185) $\left(x_{1}=97.9 \mu \mathrm{m}, x_{2}=\right.$ $\left.73.5 \mu \mathrm{m}, I_{1}=160.1 \mu \mathrm{m}, I_{2}=195.4 \mu \mathrm{m}\right)$ and sma-1(e30) $\left(x_{1}=69.8 \mu \mathrm{m}, x_{2}=46.1 \mu \mathrm{m}\right.$, $I_{1}=103.2 \mu \mathrm{m}, I_{2}=110.9 \mu \mathrm{m}$ ) mutants (Figure $2 \mathrm{E}$ ), giving $v_{0}=13.9 \mu \mathrm{m} / \mathrm{hr}$ and $v_{0}=9.3$ $\mu \mathrm{m} / \mathrm{hr}$, respectively. Assuming a linear relationship between velocity and body size,

$$
v_{0}=m l_{2}+b \text {, }
$$

the two values of $v_{0}$ and $I_{2}$ imply $m=0.054 \mathrm{hr}^{-1}$ and $b=3.3 \mu \mathrm{m} / \mathrm{hr}$. Recognizing that $l_{2}$ $=I_{0}+u t_{2}$, Eq. 10 becomes 


$$
v_{0}=m\left(l_{0}+u t_{2}\right)+b,
$$

322 with $u t_{2}=35 \mu \mathrm{m}$ (Figure S2E). Figure $2 \mathrm{C}$ (purple curve) shows $p$ versus $I_{0}$ from Eq. 5 $323(t>T)$ with Eq. 11 inserted for $v_{0}$.

324

325 Statistical analyses, plots and raw data:

326 Statistical analyses and plots were performed using $R$ version 3.5.2 ( $R$ core Team, 327 2018), $R$ studio version 1.1.463 (RStudio Team, 2015) and the following packages: car 328 (Fox and Weisberg, 2019), ImerTest (Kuznetsova et al., 2017), Rmisc (Hope, 2013), 329 ggplot2 (Wickham, 2016), ggstance (Henry et al., 2019), ggrepel (Slowikowski, 2019). 330 The distribution of QR.pax final position in Figure 1, 3A and Figure S2B was 331 represented with ggridges (Wilke, 2018) using a bandwidth of 0.25 for smoothing. Raw 332 data and summary are presented in the Supplementary Table. 


\section{Results}

334 Variance in QR.pax final position is similar to that of other migrating neurons

335 The sensitivity to noise, or stochastic variation, is measured by the variance of a trait 336 in a population of isogenic individuals in a constant environment. We first compared in $337 \mathrm{~N} 2$ and three genetically distinct wild isolates the variance in QR.pax final position to 338 that of other neurons that migrate during embryogenesis: BDU, ALM, CAN and HSN 339 (Sulston et al., 1983; Hedgecock et al., 1987) (Figure 1C,D). The cell body position of 340 these neurons can be measured in the same animals with the same scale as that of 341 QR.pax (Harris et al., 1996; Forrester and Garriga, 1997; Ch'ng et al., 2003; Zinovyeva and Forrester, 2005; Zinovyeva et al., 2008). QR.pax final position variance is similar

343 within the four strains $(F=0.48, p=1)$ and the two replicates $(F=0.15, p=1)$ but not 344 among the six neurons $\left(F=37.8, p<10^{-15}\right)$. BDU has significantly lower variance than 345 the other migrating neurons, which is likely to reflect the fact that it only migrates at a 346 short range (Figure 1D). The variance of QR.pax is similar to those of CAN ( $F=5.5$, $347 p=0.19)$ and $\operatorname{HSN}(F=4.4, p=0.36)$. ALM has a slightly larger variance than the other neurons $(F>9, p<0.02)$. Altogether, this result reveals that $Q R$.pax final position is quite robust to noise despite the temporal regulation of its migration endpoint. Note that among wild isolates, we do not observe consistent co-variation between migrating neurons except for QR.paa and QR.pap (Suppl. Table). This also imply that using QR.pax as the mean position between QR.paa and QR.pap is relevant.

Temperature mildly affects the mean position of QR.pax, while early developmental

We tested two ecologically relevant environmental variables for their effect on QR.pax positioning: temperature and starvation at hatching. Temperature can affect various developmental processes. Plates containing $\mathrm{L} 1$ larvae were transferred from $20^{\circ} \mathrm{C}$ to different temperatures $\left(15^{\circ} \mathrm{C}, 20^{\circ} \mathrm{C}\right.$ or $\left.25^{\circ} \mathrm{C}\right)$ one generation before scoring. The same

360 four strains were scored as above. The major effect on the final positioning is due to 361 the genotype $\left(X^{2}=568.67, p<10^{-15}\right)$. The temperature shifts QR.pax final position $\left(X^{2}=66.93, p<10^{-15}\right)$ but the strength of this effect is slightly modulated by the genotype (genotype $x$ temperature interaction: $\left.X^{2}=16.23, p=0.001\right)$. The temperature shifts 364 QR.pax final position toward the anterior as the temperature decreased, with a value 
of 0.04 relative position unit per degree (Figure $1 \mathrm{~F})$. This value decreases to 0.03 in the genotype XZ1516, 0.01 in the genotype EG4725 and CX11314, suggesting a lesser sensitivity to temperature in the two last wild isolates. Note that temperature is not a specific environmental variable as it may affect many processes in the larva.

After hatching in the absence of food, larvae of Caenorhabditis elegans stop their development, a phenomenon known as the $L 1$ arrest, regulated by insulin signaling (Kaplan and Baugh, 2016; Zheng et al., 2018). Development starts again when the larvae ingest food, but various developmental processes may not be tightly synchronized and many traits may be affected (Lee et al., 2012). We maintained recently hatched larvae under food deprivation for two days in crowded plates. We then provided them with food and scored them six to eight hours later, once QR.paa had reached the ventral part of the animal, QR.pap the dorsal part (and thus both had stopped their migration) and the $\mathrm{V}$ seam cells had divided once. The variance among the different fed strains was similar $(F=0.48, p=1)$ as well as the variance among the starved strains $(F=2.1, p=0.30)$. Nonetheless, starvation increased considerably the variance in the starved treatment compared to continuously fed worms $\left(F=13.37, p<10^{-}\right.$ $\left.{ }^{14}\right)$ (Figure 1E). Note that after L1 starvation, the variance of other neurons does not seem to be largely altered, especially in XZ1516 (Figure 1C).

Differences in final cell position may result in downstream differentiation phenotypes, such as variation in axon morphology in the case of neurons. QR.paa becomes the AVM mechanosensory neuron. We thus monitored axons of mechanosensory neurons after starvation of GOU174, a strain exhibiting a GFP reporter in mechanosensory neurons including AVM (see Methods). We scored larvae at the L3 stage and used the AVM cell body as a landmark. In these conditions, the variance of $A V M$ is also higher after starvation in the L3 stage compared to the control $\left(F=22.6, p<10^{-5}\right)$ (Figure S1A). Out of 200 animals in each condition, we only observed three animals with defects in axon (defasciculation, hook or extra branching) in the control population and also three after starvation. Axon formation is thus robust to early starvation and differences in cell position. Nonetheless, we found that AVM cell body

394 (Figure S1C) or projection (Figure S1D) was more frequently in the vicinity of PLM projection after starvation $\left(L R X^{2}=16.8, p<10^{-4}\right)$. An overlap between PLM projection and ALM has been previously observed in sax-1 and sax-2 mutants (Gallegos and 
398 interestingly, we found that this close proximity (overlapping) is more prone to appear when AVM is posterior $\left(L R X^{2}=22.9, p<10^{-5}\right)$ (Figure S1A).

\section{QR.pax final position is sensitive to body size}

402 The end of QR.pa migration relies on the timing of expression of $m i g-1$ and not the position of the cell in the animal (Mentink et al., 2014). From this observation, we can predict that body size affects QR.pax final position: in a longer body, the cell should stop at the same time, i.e. at a more posterior position; conversely in a shorter body the cell should stop at a more anterior position (Figure 2A, left). Alternatively, body size variation may be fully compensated and the relative position of QR.pax remains unchanged at various body sizes (Figure 2A, right).

We thus tested whether body size affects QR.pax position. We selected a set of mutants in the N2 reference background with a smaller or a longer egg size and without general cell migration defect (Figure S2A). These include mutants in four genes as well as tetraploid animals with an overall larger body size (C. elegans is normally diploid (Nigon, 1951a)). larp-1 encodes a La-related protein. A loss of function of this gene upregulates Ras-MAPK during oogenesis leading to smaller oocytes (Nykamp et al., 2008). The loss of function of sma-1, encoding a $\beta \mathrm{H}$-spectrin, impairs embryonic elongation and leads to smaller body size (McKeown et al., 1998). lon-1 encodes a cysteine-rich secretory protein (CRISP). Loss of function of this gene results in the upregulation of the TGF- $\beta$ pathway, increasing body size by hypodermal endoreduplication, observed in adult stage (Morita et al., 2002). It also may affect egg length by physical compression in the gonad arm (Yamamoto and Kimura, 2017) but

421 its effect on early larval development was not studied. fln-1 encodes a filamin required 422 for proper ovulation (Kovacevic and Cram, 2010). Nonetheless, how the loss of 423 function allele fln-1 (ok2611) affects egg and L1 length is unknown.

In these mutants, we measured QR.pax position and the pharynx-to-rectum (P425 to-R) distance. The empirical measurements revealed that QR.pax final position and 426 P-to-R distance are correlated, with longer animals having a more posterior QR.pax 427 relative position (Figure $2 \mathrm{~B}$ ). This indicates that, as expected from the temporal regulation of its migration endpoint, QR.pax final positioning is sensitive to body size.

We established a mathematical model of the expected final position of QR.pax as a function of body size. The larva grows during the cell migration, as measured in 
431 Suppl. Table, which is taken into account in the model (see Methods). The model 432 predicts the relationship between QR.pax position and body size at a given timepoint, 433 in the absence of compensation (Figure 2C, red curve). Compared to the best-fit model 434 without body size compensation, the empirical measurements show an effect on body 435 size on QR.pax position that is smaller than that predicted by this simple model version, 436 indicating the presence of a partial compensation mechanism.

437 We investigated two different scenarios of partial compensation to decipher the 438 relationship between body size and QR.pax final position: an adaptation of the duration 439 of migration of QR.p (but not QR.pa) to body size or an adaptation of the cell velocity 440 to body size. In the first case, given that the temporal regulation of mig-1 expression 441 occurs at the end of the migration, we hypothesize that body size would affect the last 442 part of the migration only, i.e. the short-range migration of QR.pa. Thus, the relative 443 position of QR.p division should be similar between long and short animals. 444 Measurements of the QR.p site of division (Rectum to QR.pp) and QR.pa site of 445 division (QR.pp to QR.pa) did not support this hypothesis (Figure 2D), as the relative 446 position of QR.p division is more anterior in small animals $(t=-2.4, p=0.02)$. In the 447 second scenario, one can predict a mechanism through which the cell velocity is 448 adapted to the body size, where the cell migrates faster in long animals. To estimate cell speed at different body sizes, we used the sma-1 and lon-1 mutants (the latter is close in body size to the wild-type N2; Figure 2B). We measured cell position at two timepoints during migration ( $\mathrm{t}=3 \mathrm{~h}$ after hatching and $\mathrm{t}=6 \mathrm{~h}$ after hatching) and inferred

452 cell velocity through the mathematical model, taking into account larval growth (Eq. 9).

453 We found that the migration speed of the $Q R$ lineage from $3 \mathrm{~h}$ to $6 \mathrm{~h}$ after hatching was 454 higher in Ion-1(e185); ayls9 mutants (13.9 $\mu \mathrm{m} / \mathrm{hr})$ compared to ayls9 sma-1(e30) mutants $(9.3 \mu \mathrm{m} / \mathrm{hr}$ ) (Figure $2 \mathrm{E}$ ). These results are consistent with a partial compensation mechanism of body size acting on cell velocity. Indeed, incorporating these data into the model gives good agreement with the measurements, using no free parameters (Figure 2C, purple curve).

Natural variation of QR.pax final position in wild isolates

461 QR.pax position has been studied only in the laboratory-adapted genetic background N2. The occurrence and span of natural variation for this trait was unknown. Above we 
464 measured QR.pax final position in a panel of 40 C. elegans strains (N2 and 39 wild 465 isolates) that is representative of the genetic diversity of the species (Cook et al., 2017). 466 We observed natural variation in QR.pax final position among the wild isolates (Figure $4673 \mathrm{~A}, F=18.9, p<10^{-15}$ ). The mean value of QR.pax final position in the $\mathrm{N} 2$ background 468 is close to the grand mean in the species. Some isolates revealed a more anterior 469 position (such as ECA36 and CB4932) and others a more posterior position (such as $470 \quad X Z 1516$ and JU830).

471 Considering the sensitivity of QR.pax final position to body size, we wondered 472 whether natural variation in QR.pax position was explained at least partially by 473 variation in body size. We first measured egg length as a proxy for L1 larval length that 474 is easier to measure. However, when we measured larval lengths (P-to-R distances) 475 at hatching and 6 hours after hatching in a subset of 14 strains, we realized that they 476 were surprisingly poorly correlated with egg length in natural isolates, suggesting 477 natural variation in morphogenesis within the egg shell (Figure S3A,B). Note that the 478 N2 laboratory strain has the longest P-to-R distance of the 14 tested isolates. 479 Interestingly, we did not find any correlation between QR.pax final position and body 480 size in this set of isolates, suggesting that body size did not explain the variation in 481 QR.pax final position and was thus compensated during evolution of the C. elegans 482 species (Figures 3C and S3D, E). We did not find any correlation between QR.pax 483 final position and the absolute value of the sampling latitude $(t=-0.94, p=0.35)$. 


\section{DISCUSSION}

\section{Variance in final cell position}

487 To inquire whether the temporally-regulated position of QR.pa daughters is sensitive

488 to various perturbations, we used different types of metrics. I) For most measurements, 489 we used a scale that takes as landmarks the lateral epidermal seam cells, as widely used in studies of QR/QL positioning (Coudreuse et al., 2006; Harris et al., 1996;

491 Mentink et al., 2014; Whangbo and Kenyon, 1999). Although nematodes are not segmented, their organization is formed of repeats along the antero-posterior axis, particularly strikingly of these lateral epidermal seam cells. In our scale, each such repeat along the antero-posterior is further divided in four units, with a total of 27 units between the base of the pharynx to the rectum (Figure 1B). Note that QR is born prior to hatching as the sister of the lateral epidermal seam cell V $5 R$ and therefore its starting point is always the same on this scale (Sulston et al., 1983; Hedgecock et al., 1987). II) In some cases, we measured cell position in micrometers from the base of the pharynx or from the rectum (e.g. Figure 2D,E). III) When we varied body size, we scaled the micrometer measurements to a body length measure (e.g. Figure 2D).

We find that the variance in QR.pax position, as well as the observed range, stay within the length of a repeat along body length (4 of our scale units). The range encompasses about half a repeat length (2 scale units; Figure 2). However, after starvation in the L1 stage, the observed range encompasses over a repeat length. Using better known animals as a comparison, this range of QR.pax sensitivity to stochastic noise in the starvation treatment would correspond to the antero-posterior displacement of an insect appendage to the next segment, which would be considered a dramatic homeotic transformation. Note that in this starvation experiment, we only scored animals where development of seam cells and the QR lineage was not strongly retarded (see Methods) and thus the range may be even greater if all animals were considered. The increase in variance may be explained by the fact that after a long L1 starvation period, the growth speed of the worms is affected and development is 513 delayed (Lee et al., 2012). This delay can potentially affect the timing of $V$ seam cell 514 division (Olmedo et al., 2020) as well as the intrinsic dynamics of QR migration. 515 Importantly, the fact that BDU, ALM, CAN and HSN positions are not affected by early 
516 starvation also suggests that the relative scale used to measure the final position is not 517 impaired by this treatment.

To some extent, displacements in the final position of the cell body can be compensated. For example in neurons, axon growth can be modulated according to the distance to the target by cell extrinsic determinants (Hekimi and Kershaw, 1993).

521 Nonetheless in other cases, a shift in the position of neuronal cell bodies can drastically 522 alter their fate and morphology (Martineau et al., 2018).

523 We wondered whether changes in the final position of QR.pax lead to 524 differences in downstream neuronal phenotypes. We observed that posteriorly shifted 525 AVM tends to be in the vicinity of the PLM projection after early starvation. We do not 526 know whether a synaptic connection is established between these two 527 mechanosensory neurons and whether this may be (counter)selected.

\section{A model without free parameters suggests partial compensation of body size}

We observed that cells migrate farther in the animal relative to landmarks when body size is small, and less far when it is large. This observation is qualitatively consistent

533 they will migrate a constant distance, which will be larger relative to a smaller body.

534 However, quantitatively, the degree of this effect was observed to be less than 535 predicted by the model, even for the best-fit value of the constant speed. Indeed, in 536 absolute values (microns), cells migrate farther when body size is large, and less far 537 when body size is short (Figure S3B). We therefore hypothesized that partial 538 compensation may be acting through a change in cell speed as a function of body size, 539 i.e. if QR and its progeny migrate faster at larger body size. To test this hypothesis, we 540 measured cell speed in sma-1 versus lon-1 mutants (Figure 2D) and using the model, 541 we indeed found that the partial compensation of body size did operate through a 542 change in cell speed. The improved model provided a quantitatively accurate 543 description of the measurements. Moreover, given the known inputs (cell start position, 544 cell start and stop time, cell velocity in two mutants, and larval growth speed), the 545 improved model succeeded with no fit parameters.

546 Our mathematical model is minimal in its construction yet quantitatively 547 accounts for the observations. Some simplifying assumptions are supported by the 548 data, for example the observation that all larvae, independent of mutant strain, grow a 549 constant amount in 6 hours. We have checked other assumptions explicitly; for 
example, we find that the results are negligibly changed if the cell accelerates and decelerates instead of instantaneously starting and stopping its migration. This result also suggests that our results would be robust to details such as temporal variations in cell speed or pauses due to cell division.

Possible mechanisms of cell speed dependence on body size could be the following. First, migration speed could be increased at larger cell size. Nonetheless, evidence from the literature tends to associate a negative correlation between cell size and cell velocity in vitro under adhesive conditions (Leal-Egaña et al., 2017; Hennig et al., 2020). Second, body size could affect extracellular matrix density, such that larger cells secrete a less tight matrix, resulting in faster net migration speed, as in the emb9 matrix collagen mutant (Kawano et al., 2009; Mentink et al., 2014). Third, body size could affect the properties of the Wnt gradient influencing QR migration; this could operate if for instance a larger body size resulted in stronger Wnt concentrations at a given relative position, resulting in faster cell speed (Mentink et al. 2014). Finally, it is possible that the cell speed modulation mechanism depends upon the specific mutants we used for these assays.

\section{Natural variation}

All previous studies of QR migration were performed in the laboratory-modified N2 background of $C$. elegans. Here we uncover variation in the final position of QR.paa and QR.pap when exploring a representative set of $C$. elegans wild isolates. The variance in QR.pax position appears similar in all isolates but the mean position differs from about $1 / 4$ of a body repeat (1 on our measurement scale) from CB4932 to XZ1516

573 (Figure 3A) in standard laboratory conditions. When considering different individuals,

574 QR.pax position may vary in a range of almost a full body repeat among different 575 individuals of different wild genotypes (3.75-7.5 on our scale; see Figure 3B for such 576 representative animals).

577 Body size variation in the L1 stage is substantial among wild isolates, and 578 almost covers the range of the body size mutants we used, excluding the tetraploid animals. However, we did not find a correlation between QR.pax body position and L1 body size in the subset of wild isolates we used for this analysis. This may be due to a

581 lack of power or may suggest the presence of an evolutionary compensation in QR.pax position relative to body size variation. QR velocity and its migration dynamics can be affected in a different manner in each isolate. In any case, we conclude that natural 
584 variation in QR.pax position is not fully explained by body size variation. The available

585 natural variation in QR.pax position will allow us in the future to analyze the genetic

586 basis for the observed natural variation in the final position of a long-range migrating

587 cell.

588

589 Acknowledgements: We thank Hendrik Korswagen and his laboratory for

590 discussions, as well as Michel Labouesse. We thank Hendrik Korswagen, Erik Schild

591 and Joao Picao Osorio for comments on the manuscript. Some N2 mutant strains were

592 provided by the CGC, which is funded by NIH Office of Research Infrastructure

593 Programs (P40 OD010440). We thank Wormbase. This work was funded by a

594 Collaborative Grant from the Human Frontier Science Program (RGP0030/2016).

$595 \quad$ The authors declare that they have no conflict of interests. 


\section{References}

597 Abercrombie, M., Heaysman, J.E.M., and Pegrum, S.M. (1970). The locomotion of

598 fibroblasts in culture: III. Movements of particles on the dorsal surface of the leading 599 lamella. Exp. Cell Res. 62, 389-398.

600 Altun, Z.F. and Hall, D.H. (2020) Handbook of C. elegans Anatomy. In WormAtlas. 601 http://www.wormatlas.org/hermaphrodite/hermaphroditehomepage.htm

602 Aman, A., and Piotrowski, T. (2010). Cell migration during morphogenesis. Dev. Biol. $603341,20-33$.

604 Barkai, N., and Leibler, S. (1997). Robustness in simple biochemical networks. Nature $605387,913-917$.

606 Baugh, L.R. (2013). To grow or not to grow: nutritional control of development during 607 Caenorhabditis elegans L1 Arrest. Genetics 194, 539-555.

608 Braendle, C., and Félix, M.-A. (2008). Plasticity and errors of a robust developmental 609 system in different environments. Dev. Cell 15, 714-724.

610 Branda, C.S., and Stern, M.J. (2000). Mechanisms controlling sex myoblast migration 611 in Caenorhabditis elegans hermaphrodites. Dev. Biol. 226, 137-151.

612 Brenner, S. (1974). The genetics of Caenorhabditis elegans. Genetics 77, 71-94.

613 Burke, S.L., Hammell, M., and Ambros, V. (2015). Robust distal tip cell pathfinding in 614 the face of temperature stress is ensured by two conserved microRNAs in 615 Caenorhabditis elegans. Genetics 200, 1201-1218.

616 Chalfie, M., and Sulston, J. (1981). Developmental genetics of the mechanosensory 617 neurons of Caenorhabditis elegans. Dev. Biol. 82, 358-370.

618 Ch'ng, Q., Williams, L., Lie, Y.S., Sym, M., Whangbo, J., and Kenyon, C. (2003). 619 Identification of genes that regulate a Left-Right asymmetric neuronal migration in 620 Caenorhabditis elegans. Genetics 164, 1355-1367.

621 Choy, R.K.M., and Thomas, J.H. (1999). Fluoxetine-resistant mutants in C. elegans 622 define a novel family of transmembrane proteins. Mol. Cell 4, 143-152.

623 Cook, D.E., Zdraljevic, S., Tanny, R.E., Seo, B., Riccardi, D.D., Noble, L.M., Rockman, 624 M.V., Alkema, M.J., Braendle, C., Kammenga, J.E., et al. (2016). The genetic basis of 625 natural variation in Caenorhabditis elegans telomere length. Genetics 204, 371-383. 626 Cook, D.E., Zdraljevic, S., Roberts, J.P., and Andersen, E.C. (2017). CeNDR, the 627 Caenorhabditis elegans natural diversity resource. Nucleic Acids Res. 45, D650628 D657. 
629 Coudreuse, D.Y.M., Roël, G., Betist, M.C., Destrée, O., and Korswagen, H.C. (2006).

630 Wnt gradient formation requires retromer function in Wnt-producing cells. Science 312,

$631921-924$.

632 Doitsidou, M., Reichman-Fried, M., Stebler, J., Köprunner, M., Dörries, J., Meyer, D., 633 Esguerra, C.V., Leung, T., and Raz, E. (2002). Guidance of primordial germ cell 634 migration by the chemokine SDF-1. Cell 111, 647-659.

635 Duchek, P., Somogyi, K., Jékely, G., Beccari, S., and Rørth, P. (2001). Guidance of 636 cell migration by the Drosophila PDGF/VEGF receptor. Cell 107, 17-26.

637 Ebbing, A., Middelkoop, T.C., Betist, M.C., Bodewes, E., and Korswagen, H.C. (2019). 638 Partially overlapping guidance pathways focus the activity of UNC-40/DCC along the 639 anteroposterior axis of polarizing neuroblasts. Development 146, dev180059.

640 Elowitz, M.B., Levine, A.J., Siggia, E.D., and Swain, P.S. (2002). Stochastic gene 641 expression in a single cell. Science 297, 1183-1186.

642 Endres, R.G., and Wingreen, N.S. (2008). Accuracy of direct gradient sensing by single 643 cells. Proc. Natl. Acad. Sci. 105, 15749-15754.

644 Farhadifar, R., Baer, C.F., Valfort, A.-C., Andersen, E.C., Müller-Reichert, T., Delattre, M., and Needleman, D.J. (2015). Scaling, selection, and evolutionary dynamics of the mitotic spindle. Curr. Biol. 25, 732-740.

647 Félix, M.-A., and Wagner, A. (2008). Robustness and evolution: concepts, insights and 648 challenges from a developmental model system. Heredity 100, 132-140.

649 Forrester, W.C., and Garriga, G. (1997). Genes necessary for C. elegans cell and 650 growth cone migrations. Development 124, 1831-1843.

651 Fox, J., and Weisberg, S. (2019). An $\{R\}$ Companion to Applied Regression. URL:

652 https://socialsciences.mcmaster.ca/jfox/Books/Companion/

653 Gallegos, M.E., and Bargmann, C.I. (2004). Mechanosensory neurite termination and 654 tiling depend on SAX-2 and the SAX-1 kinase. Neuron 44, 239-249.

655 Gimond, C., Vielle, A., Silva-Soares, N., Zdraljevic, S., McGrath, P.T., Andersen, E.C., 656 and Braendle, C. (2019). Natural variation and genetic determinants of Caenorhabditis 657 elegans sperm size. Genetics 213, 615-632.

658 Grimbert, S., Tietze, K., Barkoulas, M., Sternberg, P.W., Félix, M.-A., and Braendle, C. 659 (2016). Anchor cell signaling and vulval precursor cell positioning establish a 660 reproducible spatial context during C. elegans vulval induction. Dev. Biol. 416, 123661135.

662 Halfter, W., Dong, S., Yip, Y.-P., Willem, M., and Mayer, U. (2002). A critical function 
663 of the Pial Basement Membrane in cortical histogenesis. J. Neurosci. 22, 6029-6040.

664 Harris, J., Honigberg, L., Robinson, N., and Kenyon, C. (1996). Neuronal cell migration

665 in C. elegans: regulation of Hox gene expression and cell position. Development 122, 666 3117-3131.

667 Hedgecock, E.M., Culotti, J.G., Hall, D.H., and Stern, B.D. (1987). Genetics of cell and 668 axon migrations in Caenorhabditis elegans. Development 100, 365-382.

669 Hekimi, S., and Kershaw, D. (1993). Axonal guidance defects in a Caenorhabditis 670 elegans mutant reveal cell-extrinsic determinants of neuronal morphology. J. Neurosci. $67113,4254-4271$.

672 van Helvert, S., Storm, C., and Friedl, P. (2018). Mechanoreciprocity in cell migration. 673 Nat. Cell Biol. 20, 8-20.

674 Hennig, K., Wang, I., Moreau, P., Valon, L., DeBeco, S., Coppey, M., Miroshnikova, 675 Y.A., Albiges-Rizo, C., Favard, C., Voituriez, R., et al. (2020). Stick-slip dynamics of 676 cell adhesion triggers spontaneous symmetry breaking and directional migration of 677 mesenchymal cells on one-dimensional lines. Sci. Adv. 6, eaau5670.

678 Henry, L., Wickham, H., and Chang, W. (2019). ggstance: Horizontal "ggplot2" 679 Components. URL: https://CRAN.R-project.org/package=ggstance

680 Hermann, G.J., Schroeder, L.K., Hieb, C.A., Kershner, A.M., Rabbitts, B.M., Fonarev, 681 P., Grant, B.D., and Priess, J.R. (2005). Genetic analysis of lysosomal trafficking in 682 Caenorhabditis elegans. Mol. Biol. Cell 16, 3273-3288.

683 Hodgkin, J., and Doniach, T. (1997). Natural variation and copulatory plug formation in 684 Caenorhabditis elegans. Genetics 146, 149-164.

685 Hope, R.M. (2013). Rmisc: Ryan Miscellaneous. URL: https://CRAN.R686 project.org/package $=$ Rmisc

687 Inamura, N., Kimura, T., Tada, S., Kurahashi, T., Yanagida, M., Yanagawa, Y., 688 Ikenaka, K., and Murakami, F. (2012). Intrinsic and extrinsic mechanisms control the 689 termination of cortical interneuron migration. J. Neurosci. 32, 6032-6042.

690 Iwasaki, K., Liu, D.W., and Thomas, J.H. (1995). Genes that control a temperature691 compensated ultradian clock in Caenorhabditis elegans. Proc. Natl. Acad. Sci. 92, 692 10317-10321.

693 Johnson, T.E., Mitchell, D.H., Kline, S., Kemal, R., and Foy, J. (1984). Arresting 694 development arrests aging in the nematode Caenorhabditis elegans. Mech. Ageing 695 Dev. 28, 23-40.

696 Josephson, M.P., Chai, Y., Ou, G., and Lundquist, E.A. (2016). EGL-20/Wnt and MAB- 
$6975 /$ Hox act sequentially to inhibit anterior migration of neuroblasts in C. elegans. PLoS 698 ONE 11.

699 Kaplan, R.E.W., and Baugh, L.R. (2016). L1 arrest, daf-16/FoxO and nonautonomous 700 control of post-embryonic development. Worm 5.

701 Kawano, T., Zheng, H., Merz, D.C., Kohara, Y., Tamai, K.K., Nishiwaki, K., and Culotti, 702 J.G. (2009). C. elegans mig-6 encodes papilin isoforms that affect distinct aspects of 703 DTC migration, and interacts genetically with mig-17 and collagen IV. Development 704 136, 1433-1442.

705 Kikuchi, T., Shibata, Y., Kim, H.-S., Kubota, Y., Yoshina, S., Mitani, S., and Nishiwaki, 706 K. (2015). The BED finger domain protein MIG-39 halts migration of distal tip cells in 707 Caenorhabditis elegans. Dev. Biol. 397, 151-161.

708 Kim, M., Bjorke, B., and Mastick, G.S. (2019). Motor neuron migration and positioning 709 mechanisms: New roles for guidance cues. Semin. Cell Dev. Biol. 85, 78-83.

710 Kovacevic, I., and Cram, E.J. (2010). FLN-1/Filamin is required for maintenance of 711 actin and exit of fertilized oocytes from the spermatheca in C. elegans. Dev. Biol. 347, 712 247-257.

713 Kuznetsova, A., Brockhoff, P.B., and Christensen, R.H.B. (2017). \{lmerTest\} Package:

714 Tests in linear mixed effects models. J. Stat. Softw. 82, 1-26.

715 Lau, S., Feitzinger, A., Venkiteswaran, G., Wang, J., Lewellis, S.W., Koplinski, C.A., 716 Peterson, F.C., Volkman, B.F., Meier-Schellersheim, M., and Knaut, H. (2020). A 717 negative-feedback loop maintains optimal chemokine concentrations for directional 718 cell migration. Nat. Cell Biol. 22, 266-273.

719 Leal-Egaña, A., Letort, G., Martiel, J.-L., Christ, A., Vignaud, T., Roelants, C., Filhol, 720 O., and Théry, M. (2017). The size-speed-force relationship governs migratory cell 721 response to tumorigenic factors. Mol. Biol. Cell 28, 1612-1621.

722 Lee, D., Zdraljevic, S., Cook, D.E., Frézal, L., Hsu, J.-C., Sterken, M.G., Riksen, J.A.G., 723 Wang, J., Kammenga, J.E., Braendle, C., et al. (2019). Selection and gene flow shape 724 niche-associated variation in pheromone response. Nat. Ecol. Evol. 3, 1455-1463.

725 Lee, I., Hendrix, A., Kim, J., Yoshimoto, J., and You, Y.-J. (2012). Metabolic rate 726 regulates L1 longevity in C. elegans. PLOS ONE 7, e44720.

727 L'Hernault, S.W., Shakes, D.C., and Ward, S. (1988). Developmental genetics of 728 chromosome I spermatogenesis-defective mutants in the nematode Caenorhabditis 729 elegans. Genetics 120, 435-452.

730 Madl, J.E., and Herman, R.K. (1979). Polyploids and sex determination in 
731 Caenorhabditis elegans. Genetics 93, 393-402.

732 Marks, M.E., Castro-Rojas, C.M., Teiling, C., Du, L., Kapatral, V., Walunas, T.L., and

733 Crosson, S. (2010). The genetic basis of laboratory adaptation in Caulobacter

734 crescentus. J. Bacteriol. 192, 3678-3688.

735 Martineau, F.S., Sahu, S., Plantier, V., Buhler, E., Schaller, F., Fournier, L., Chazal, 736 G., Kawasaki, H., Represa, A., Watrin, F., et al. (2018). Correct laminar positioning in 737 the neocortex influences proper dendritic and synaptic development. Cereb. Cortex N. 738 Y. NY 28, 2976-2990.

739 McAdams, H.H., and Arkin, A. (1997). Stochastic mechanisms in gene expression. 740 Proc. Natl. Acad. Sci. 94, 814-819.

741 McGrath, P.T., Rockman, M.V., Zimmer, M., Jang, H., Macosko, E.Z., Kruglyak, L., 742 and Bargmann, C.I. (2009). Quantitative mapping of a digenic behavioral trait 743 implicates globin variation in C. elegans sensory behaviors. Neuron 61, 692-699.

744 McKeown, C., Praitis, V., and Austin, J. (1998). sma-1 encodes a betaH-spectrin 745 homolog required for Caenorhabditis elegans morphogenesis. Development 125, 746 2087-2098.

747 Meighan, C.M., and Schwarzbauer, J.E. (2007). Control of C. elegans hermaphrodite 748 gonad size and shape by vab-3/Pax6-mediated regulation of integrin receptors. Genes 749 Dev. 21, 1615-1620.

750 Mentink, R.A., Middelkoop, T.C., Rella, L., Ji, N., Tang, C.Y., Betist, M.C., 751 van Oudenaarden, A., and Korswagen, H.C. (2014). Cell intrinsic modulation of Wnt 752 signaling controls neuroblast migration in C. elegans. Dev. Cell 31, 188-201.

753 Middelkoop, T.C., and Korswagen, H.C. (2014). Development and migration of the C. 754 elegans $Q$ neuroblasts and their descendants. WormBook 1-23.

755 Morita, K., Flemming, A.J., Sugihara, Y., Mochii, M., Suzuki, Y., Yoshida, S., Wood, 756 W.B., Kohara, Y., Leroi, A.M., and Ueno, N. (2002). A Caenorhabditis elegans TGF- $\beta$, 757 DBL-1, controls the expression of LON-1, a PR-related protein, that regulates 758 polyploidization and body length. EMBO J. 21, 1063-1073.

759 Nigon, V. (1951a). Polyploïdie expérimentale chez un nématode libre, Rhabditis 760 elegans Maupas. Bull Biol Fr Belg 85, 187-225.

761 Nykamp, K., Lee, M.-H., and Kimble, J. (2008). C. elegans La-related protein, LARP762 1, localizes to germline $P$ bodies and attenuates Ras-MAPK signaling during 763 oogenesis. RNA 14, 1378-1389.

764 Olmedo, M., Mata-Cabana, A., Rodríguez-Palero, M.J., García-Sánchez, S., 
Fernández-Yañez, A., Merrow, M., and Artal-Sanz, M. (2020). Prolonged quiescence delays somatic stem cell-like divisions in Caenorhabditis elegans and is controlled by insulin signaling. Aging Cell 19, e13085.

Olsen, A., Vantipalli, M.C., and Lithgow, G.J. (2006). Checkpoint proteins control survival of the postmitotic cells in Caenorhabditis elegans. Science 312, 1381-1385. Ou, G., and Vale, R.D. (2009). Molecular signatures of cell migration in C. elegans Q neuroblasts. J. Cell Biol. 185, 77-85.

772 Paksa, A., Bandemer, J., Hoeckendorf, B., Razin, N., Tarbashevich, K., Minina, S., 773 Meyen, D., Biundo, A., Leidel, S.A., Peyrieras, N., et al. (2016). Repulsive cues combined with physical barriers and cell-cell adhesion determine progenitor cell positioning during organogenesis. Nat. Commun. 7, 1-14.

Pani, A.M., and Goldstein, B. (2018). Direct visualization of a native Wnt in vivo reveals that a long-range Wnt gradient forms by extracellular dispersal. ELife 7, e38325. R core Team (2018). R: A Language and Environment for Statistical Computing. URL: 779 https://www.R-project.org/.

780 Rabbitts, B.M., Ciotti, M.K., Miller, N.E., Kramer, M., Lawrenson, A.L., Levitte, S., 781 Kremer, S., Kwan, E., Weis, A.M., and Hermann, G.J. (2008). glo-3, a Novel 782 Caenorhabditis elegans gene, is required for lysosome-related organelle biogenesis. 783 Genetics 180, 857-871.

784 Rella, L., Fernandes Póvoa, E.E., and Korswagen, H.C. (2016). The Caenorhabditis 785 elegans $Q$ neuroblasts: A powerful system to study cell migration at single-cell resolution in vivo. Genesis 54, 198-211.

787 Ridley, A.J., Schwartz, M.A., Burridge, K., Firtel, R.A., Ginsberg, M.H., Borisy, G., 788 Parsons, J.T., and Horwitz, A.R. (2003). Cell migration: Integrating signals from front 789 to back. Science 302, 1704-1709.

790 Rohrschneider, M.R., and Nance, J. (2013). The union of somatic gonad precursors 791 and primordial germ cells during C. elegans embryogenesis. Dev. Biol. 379, 139-151. 792 RStudio Team (2015). RStudio: Integrated development environment for R. URL 793 http://www.rstudio.com/.

794 Sato, M., Sato, K., Liou, W., Pant, S., Harada, A., and Grant, B.D. (2008). Regulation 795 of endocytic recycling by $C$. elegans Rab35 and its regulator RME-4, a coated-pit 796 protein. EMBO J. 27, 1183-1196.

797 Slowikowski, K. (2019). ggrepel: Automatically position non-overlapping text labels 798 with "ggplot2." URL: https://CRAN.R-project.org/package=ggrepel 
799 Spudich, J.L., and Koshland, D.E. (1976). Non-genetic individuality: chance in the 800 single cell. Nature 262, 467-471.

801 Stanley, C.E., and Kulathinal, R.J. (2016). Genomic signatures of domestication on 802 neurogenetic genes in Drosophila melanogaster. BMC Evol. Biol. 16, 6.

803 Sterken, M.G., Snoek, L.B., Kammenga, J.E., and Andersen, E.C. (2015). The 804 laboratory domestication of Caenorhabditis elegans. Trends Genet. 31, 224-231.

805 Sulston, J.E., and Horvitz, H.R. (1977). Post-embryonic cell lineages of the nematode, 806 Caenorhabditis elegans. Dev. Biol. 56, 110-156.

807 Sulston, J.E., Schierenberg, E., White, J.G., and Thomson, J.N. (1983). The embryonic 808 cell lineage of the nematode Caenorhabditis elegans. Dev. Biol. 100, 64-119.

809 Svitkina, T. (2018). The actin cytoskeleton and actin-based motility. Cold Spring Harb. 810 Perspect. Biol. 10, a018267.

811 Szabó, A., and Mayor, R. (2018). Mechanisms of neural crest migration. Annu. Rev. 812 Genet. 52, 43-63.

813 The C. elegans Deletion Mutant Consortium (2012). Large-Scale Screening for 814 Targeted Knockouts in the Caenorhabditis elegans Genome. G3 Genes Genomes 815 Genet. 2, 1415-1425.

816 Whangbo, J., and Kenyon, C. (1999). A Wnt signaling system that specifies two 817 patterns of cell migration in C. elegans. Mol. Cell 4, 851-858.

818 White, J.G., Southgate, E., Thomson, J.N., and Brenner, S. (1986). The structure of 819 the nervous system of the nematode Caenorhabditis elegans. Philos. Trans. R. Soc. 820 Lond. B Biol. Sci. 314, 1-340.

821 Wickham, H. (2016). ggplot2: elegant graphics for data analysis. Springer-Verlag New 822 York.

823 Wilke, C.O. (2018). ggridges: Ridgeline Plots in "ggplot2." URL: https://CRAN.R824 project.org/package $=$ ggridges

825 Yamamoto, K., and Kimura, A. (2017). An asymmetric attraction model for the diversity 826 and robustness of cell arrangement in nematodes. Development 144, 4437-4449.

827 Zheng, S., Chiu, H., Boudreau, J., Papanicolaou, T., Bendena, W., and Chin-Sang, I. 828 (2018). A functional study of all 40 Caenorhabditis elegans insulin-like peptides. J. Biol. 829 Chem. 293, 16912-16922.

830 Zinovyeva, A.Y., and Forrester, W.C. (2005). The C. elegans Frizzled CFZ-2 is 831 required for cell migration and interacts with multiple Wnt signaling pathways. Dev. 832 Biol. 285, 447-461. 
833 Zinovyeva, A.Y., Yamamoto, Y., Sawa, H., and Forrester, W.C. (2008). Complex

834 network of wnt signaling regulates neuronal migrations during Caenorhabditis elegans

835 development. Genetics 179, 1357-1371.

836 Zhu, Z., Chai, Y., Jiang, Y., Li, W., Hu, H., Li, W., Wu, J.-W., Wang, Z.-X., Huang, S.,

837 and Ou, G. (2016). Functional Coordination of WAVE and WASP in C. elegans

838 Neuroblast Migration. Dev. Cell 39, 224-238. 


\section{Figure legends}

Figure 1: QR.p neuroblast migration during the L1 stage and its sensitivity to noise and environmental variations

843 A) Nomarski micrograph of a late L1 larva, where QR.pap and QR.paa have reached

844 their final position. The relevant cells are outlined. B) Illustration of QR.p neuroblast 845 migration during the L1 stage showing the final position of QR.paa and QR.pap and 846 the relative scale used in scoring their position. This relative scale from 0 to 27 was 847 constructed relative to the seam cells, as shown here. C) Sensitivity of QR.pax final position to noise. We measured the final position of QR.pax and that of other neurons that migrate, albeit on shorter distances during embryogenesis: BDU, ALM, CAN and HSN. Black dots and error bars represent the mean and standard deviation (SD), respectively; $n=70$ per strain, 2 replicates merged. Letters a,b,c represent groups of cells with similar variance (Levene's test for homogeneity of variance). The two bottom panels show final position between neuron positions after early L1 starvation. D)

854 Illustration of BDU, ALM, CAN and HSN migration during embryogenesis, adapted 855 from Altun and Hall (2020). E) Sensitivity of QR.pax to a starvation treatment in the L1 stage. After food depletion, arrested larvae were kept starved for two days before being fed again and allowed to develop. Black dots and error bars represent the mean and $\mathrm{SD} ; \mathrm{n} \geq 40$ per strain and condition. (Levene's test for homogeneity of variance, ${ }^{* * *} \mathrm{p}$ value < 0.001). F) Robustness of QR.pax to temperature. Plates containing L1 larvae were transferred from $20^{\circ} \mathrm{C}$ to different temperatures one generation before scoring. Correlation between QR.pax final position and the growth temperature of different wild genotypes, in three independent replicate experiments. Black dots and error bars represent the mean and SD of each replicate, the colored lines represent the regression line with the associated equation estimated with a linear mixed model. $\left(\mathrm{n} \geq 40\right.$ per strain, temperature and replicate, $\left.{ }^{* * *}: p<0.001,{ }^{*}: p<0.05\right)$.

867 Figure 2: Sensitivity of QR.pax position to body size.

868 A) Schematics of the relative position of QR.pax in a long versus a short animal in the absence of body size compensation (left), with full compensation (right) or with a partial 
872 dots represent one round of subsampling of the data. Black dots and error bars

873 represent the mean and confidence intervals $(\mathrm{Cl} 95 \%)$ from the data for each

874 genotype. The black line represents the regression line from the data. The grey area

875 represents regression lines after each iteration of subsampling. C) Mathematical model

876 of the relationship between QR.pax final position and Pharynx-to-Rectum distance

877 assuming full body size compensation, no compensation (with one fit parameter, cell

878 velocity), or partial compensation (with no fit parameters). D) Location of QR.p and

879 QR.pa divisions in ayls9 sma-1 and lon-1; ayls9 backgrounds, in absolute value of

880 distance to the rectum and pharynx or scaled relatively to body size (E). The apoptotic

881 body of the QR.pp cell marks the site of QR.p division. Bars and error bars represent

882 the mean and confidence intervals (95\%) per genotype; $n>20$ per strain. Two-sided t-

883 test: ${ }^{* *}: p<0.001,{ }^{*}: p<0.05$, $p$.s.: not significant. F) Absolute distances between the

884 rectum, QR cell* and the pharynx $3 \mathrm{~h}$ and $6 \mathrm{~h}$ after hatching in lon-1; ayls9 and ayls9

885 sma-1 animals. At $3 \mathrm{~h} \mathrm{QR}^{*}$ is either QR or QR.p in some animals, at $6 \mathrm{~h} \mathrm{QR}^{*}$ is either

886 QR.p division or QR.pa in lon-1; ayls9 and mostly QR.p in ayls9 sma-1. Bars and error

887 bars represent the mean and confidence intervals (95\%) per genotype; $n \geq 10$ per

888 genotype. The cell velocity $v$ was calculated with the Eq. 9.

889

890 Figure 3: Natural variation of QR.pax final position in C. elegans.

891 A) Natural variation of QR.pax final position in a panel of 40 C. elegans wild isolates.

892 Grey dots represent QR.pax final position for each animal; black dots and error bars

893 represent the mean and SD per genotype, respectively ( $n=50$ per strain). The red

894 dashed line indicates the grand mean over the 40 isolates. B) Nomarski micrograph of

895 late L1 larvae showing an example of posterior (strain XZ1516, top) and an anterior

896 (strain EG4725, bottom) QR.pax relative position. C) Relationship between QR.pax

897 final position and Pharynx-to-Rectum distance at hatching in a subset of the panel.

898 Blue and green dots represent the mean after one round of subsampling. Black dots

899 and error bars represent the mean and $\mathrm{Cl}$ (95\%) for each genotype from the data. The

900 black line represents the regression line from the data. The grey area represents

901 regression lines after each iteration of subsampling. 
902 Supplementary figure 1: A) PLM projection overlaps with posteriorly shifted AVM 903 after early starvation. Color dots represent the relative position of AVM for each animal, 904 where its cell body or projection overlaps with PLM projection (light blue) or not (pink). 905 Black dots and error bars represent the mean and SD of the two conditions (starved and non-starved); n=100 per replicate and condition, two replicates merged. The color dots associated with colored error bars represent the mean and SD of the overlapping (red) and non-overlapping (blue) distribution. B-D) Fluorescent pictures of animals at 909 the L3 stage (GOU174 strain with GFP reporter in mechanosensory neurons). Without 910 early starvation, PLM projection stops posteriorly to ALM and AVM cell body (B). After early developmental arrest, the projection of PLM can overlap with AVM cell body (C) or AVM projection (D).

Supplementary figure 2: A) Egg size measurements of mutants chosen to potentially affect egg size. WT: wild type, i.e. N2 reference background for all mutant lines. Black dots and error bars represent the mean and SD per genotype( $n>20$ per strain). Twosided t-test comparison against WT with Bonferroni correction of the p-values. B) QR.pax final position in mutants showing a different egg size length. Grey dots represent QR.pax final position of each animal; black dots and error bars represent the mean and SD per genotype, respectively ( $n>40$ per genotype). Two-sided t-test comparison against WT with Bonferroni correction of the $p$-values. ${ }^{* *}: p<0.001,{ }^{*}$ : $p<0.05$. C-D) Relationships between egg length, pharynx-to-rectum ( $P$-to-R) distance at 0 and $6 \mathrm{~h}$ after hatching and QR.pax final position in N2 (green) and its size mutants (pink) Black dots and error bars represent the mean and confidence intervals (95\%) for each genotype. The black line represents the regression line from the data, with the associated equation. Each color dot represents the mean position after random subsampling of 20 animals and the grey area represents regression lines after each iteration of subsampling (1000 iterations). $P^{\prime}$ and $R^{2}$ adj are the median of $P$ and $R^{2}$ adj' after 1000 iterations.

931 Supplementary figure 3: Relationships between egg length, pharynx-to-rectum ( $P$ to-R) distance at 0 and 6h after hatching and QR.pax final position in N2 (green) and 933 a subset of wild isolates (blue). Black dots and error bars represent the mean and confidence intervals (95\%) for each genotype. The black line represents the regression line from the data, with the associated equation. Each color dot represents the mean 
936 position after random subsampling of 20 animals and the grey area represents 937 regression lines after each iteration of subsampling (1000 iterations). $P^{\prime}$ and $R^{2}$ adj are 938 the median of $P$ and $R^{2}$ adj ' after 1000 iterations.

939

940 Supplementary Table

941 Raw data and summary of: QR.pax, BDU, ALM, CAN and HSN final position

942 measurements for the robustness to noise (sheet 1), QR.pax final position 943 measurement for the robustness to temperature (2a) and starvation (2b), AVM 944 distance, overlap and defect count (3),natural variation in the panel of 40 strains (4), 945 egg length measurements (5), Pharynx to rectum distance at hatching and 6h after 946 hatching (6), QR.pax final position in N2 mutants (7), QR.p and QR.pa site of divisions 947 (8) and cell velocity (9). 


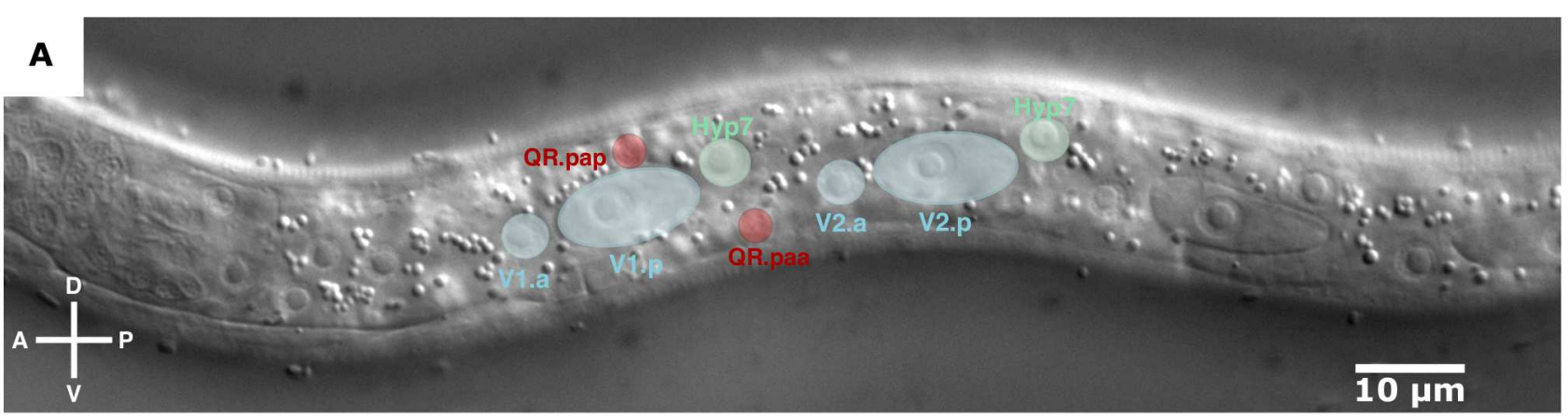

B

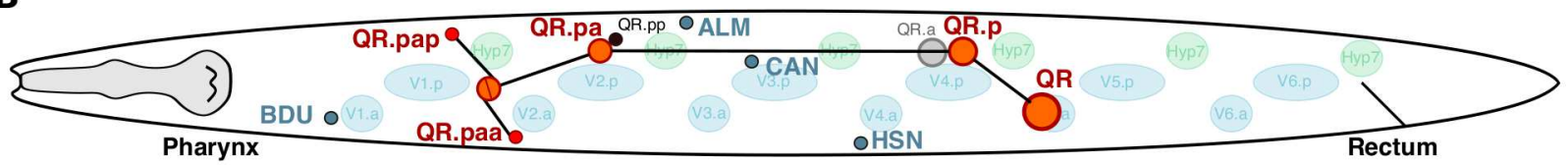

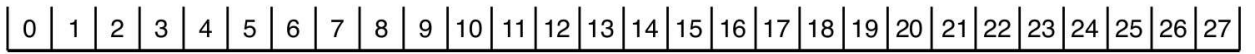

C

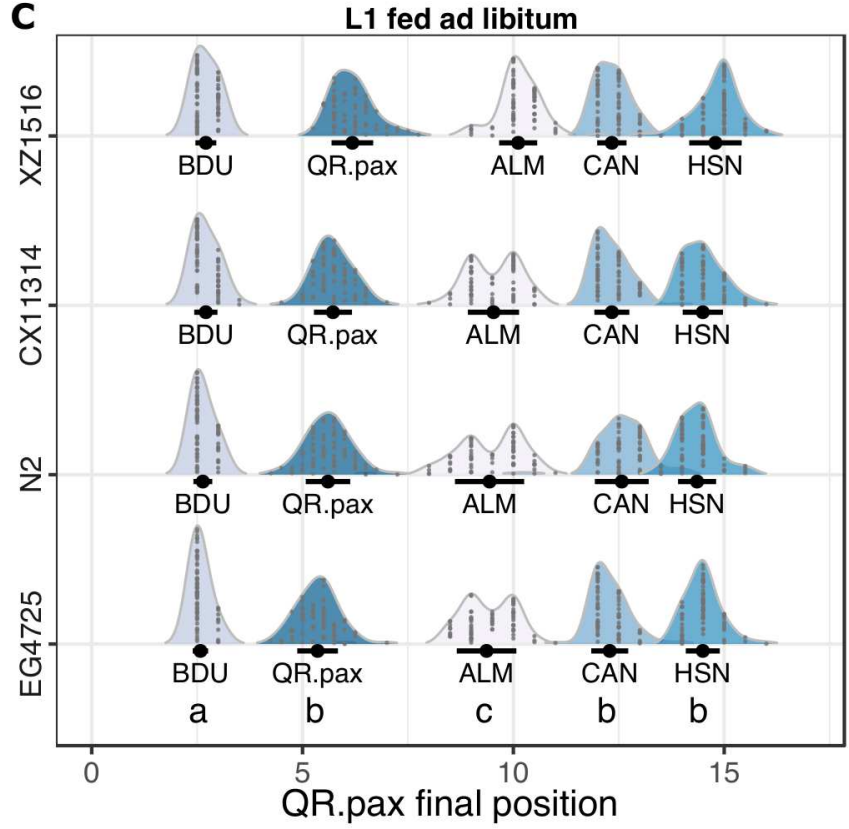

E
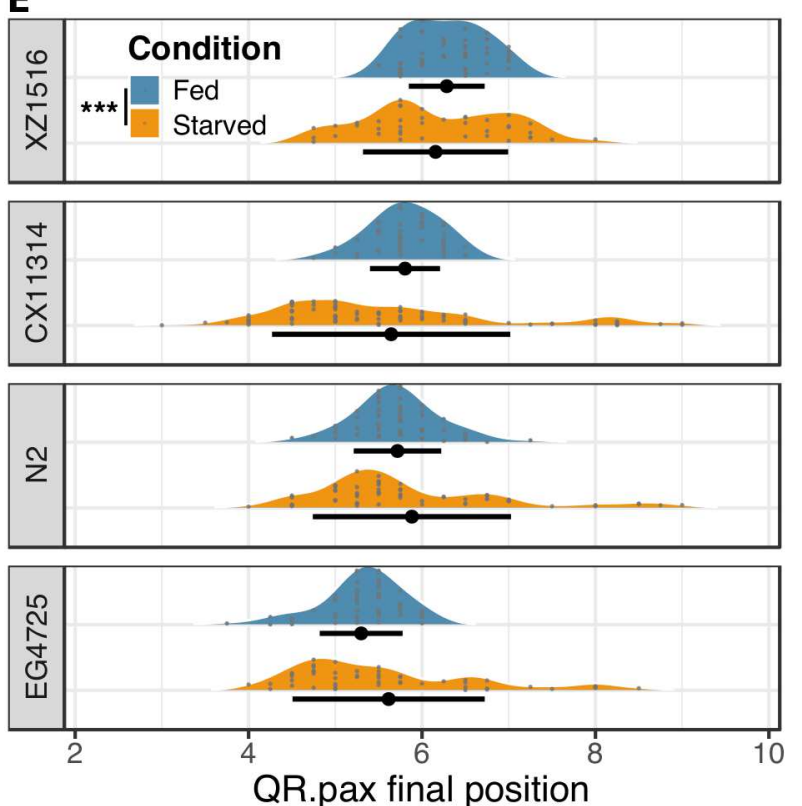

F



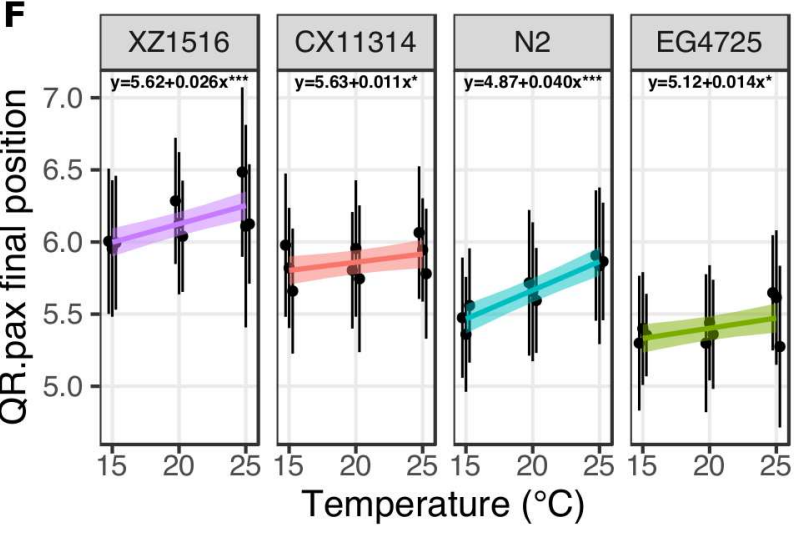


A

No compensation

Partial compensation

Total compensation

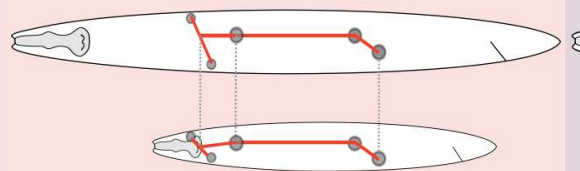

Different relative position Same distance of migration
Different relative position Different distance of migration

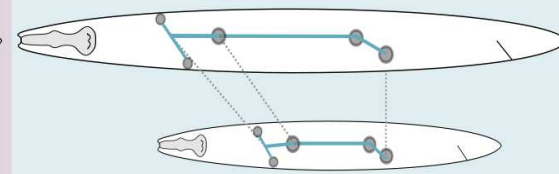

Same relative position

Different distance of migration
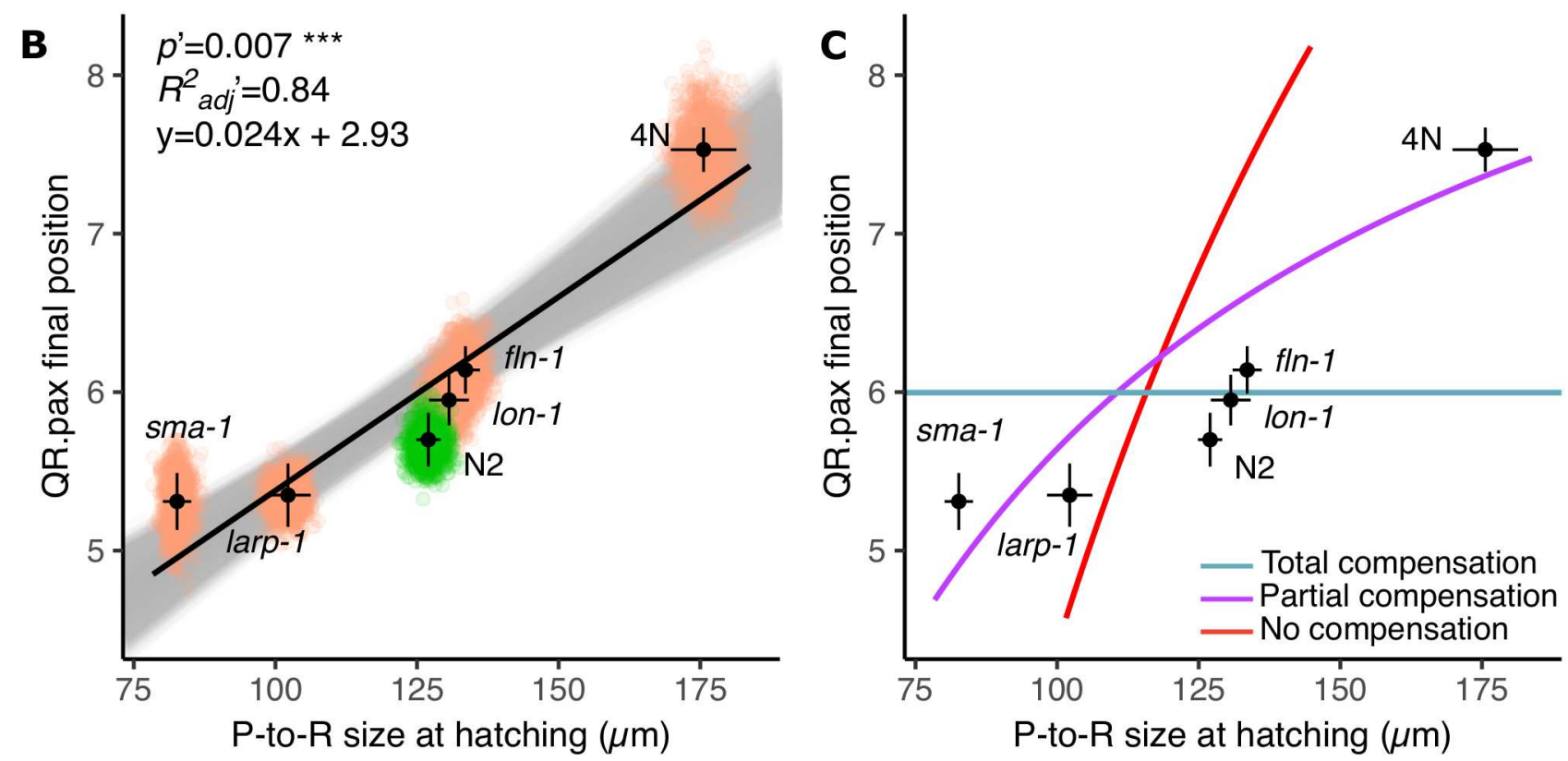

D
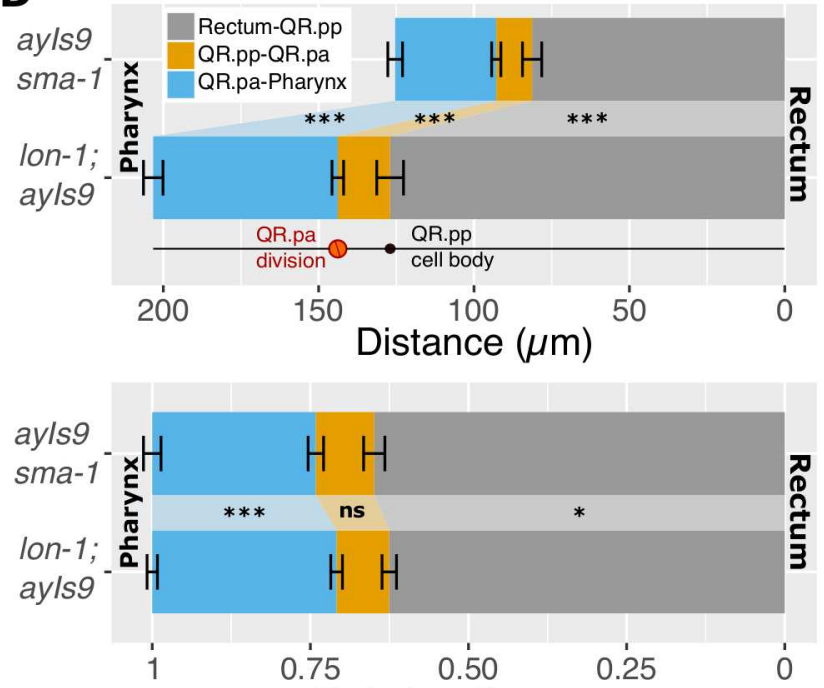

Relative distance (distance / total distance)

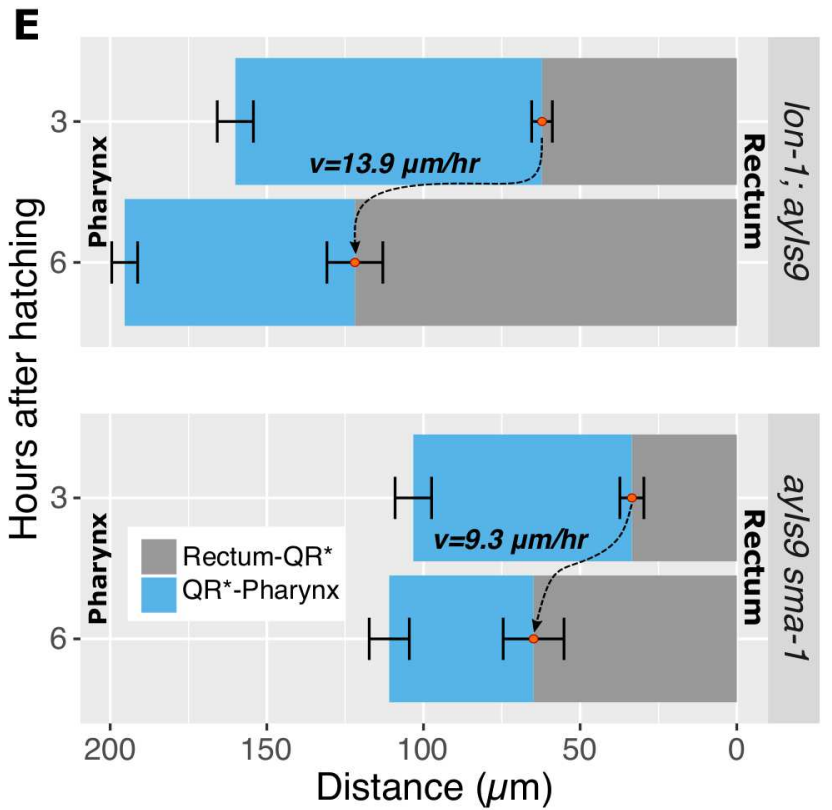



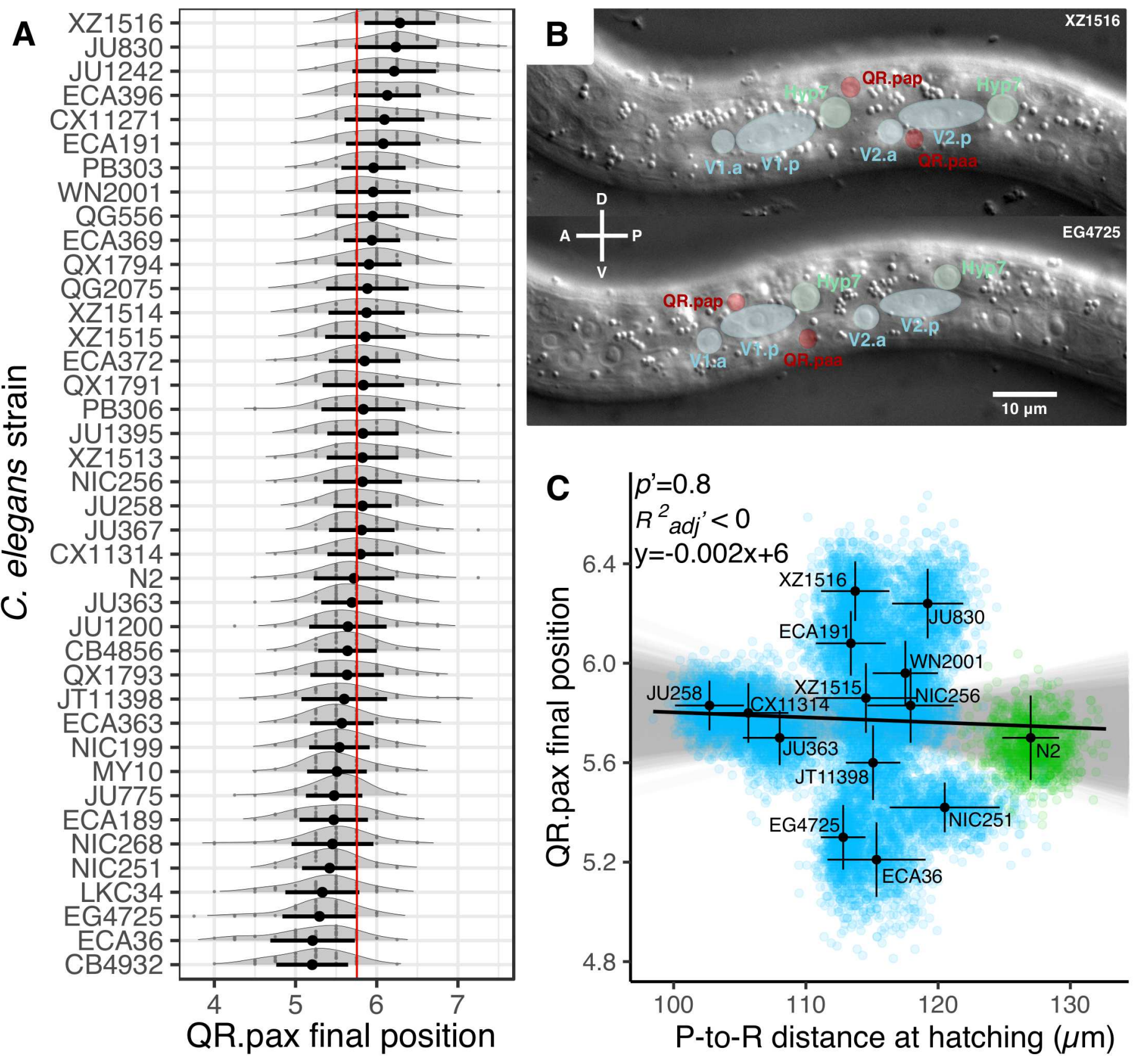